\title{
The implementation of the European Commission recommendation on open access to scientific information: Comparison of national policies
}

\author{
Lisiane Lomazzi * and Ghislaine Chartron \\ CNAM-DICEN, Paris, France
}

\begin{abstract}
Two years after the publication of the European Commission recommendation on open access to scientific information, the critical threshold of accessibility to fifty percent of papers has been crossed. However, this figure is an average and the implementation of the EC recommendation varies from one country to another. The topical issue now is to observe the different steps of implementation and to wonder about the reasons of such a disparity. In order to suggest many elements of the response, this research compares the different levels of implementation in the EU28.
\end{abstract}

Keywords: Academic publishing, open access, scientific information, policy, European Commission

\section{Introduction}

Contrary to what the European Commission might expect further to its communication [6] and its recommendation [7] (concerning open access to and preservation of scientific information within the framework Horizon 2020) after being published dated 17th July 2012 its implementation by national governments and EU research funders have not led to a standardization of open access policies. This recommendation has undergone all manner of implementations concerning the level of incentive (from recommendation to legal obligation), the contents which are concerned (from articles published in peerreviewed journals to chapters in multi-author books or entire monographs, etc.), the embargo periods (from a deposit after acceptation or at the time of publication to embargo periods up to 24 months), etc.

Despite a clear definition of the EC expectations regarding "policies to be developed by Member States [which] should be defined at national or subnational level depending on the constitutional situation and the distribution of responsibilities for defining research policy" [7] and "ensure that research funding institutions responsible for managing public research funding and academic institutions receiving public funding implement the policies by defining institutional policies for the dissemination of and open access to scientific publications and establishing implementation plans at the level of those funding institutions" [7], the open access policies heterogeneousness is an actual fact.

As it is stressed by the ERA progress report 2013 [5] "It is necessary that Member States adopt national strategies regarding access to and preservation of scientific information. To this end, consensus

\footnotetext{
*Corresponding author. E-mail: lisianelomazzi@ hotmail.fr.
} 
between major stakeholders (funders, universities, research centres, memory institutions, etc.) is necessary and should lead to shared policy principles aligned with EC recommendations".

First and foremost this paper propose doing a comparison between the national implementations of the $\mathrm{CE}$ recommendation in the EU28. The suggested analysis is a good example of its various interpretations and implementations. We compare the adopted action plans and their methods: mandatory deposit and national recommendation, delegation to each institution and research funder, national consultation of stakeholders' opinion, no policy at all.

\section{Methodology}

This study was conducted from bibliographical resources on open access in the EU28 collected via the search engine called BASE [2] and other information from the OPENAIRE [15] portal and the UNESCO Global Access Portal [9].

\section{The implementation of the recommendation at national level}

Despite the EC recommendations we notice that there are four levels of implementation: no national open access mandate and policy, consultation in progress to implement a national policy, funders mandates and policy, coordinated national policy by a recommendation or an act.

\subsection{No national open access mandate and policy}

The European countries that have not implement a national open access policy are: Romania, Cyprus, Greece, Estonia, Bulgaria, Malta, Slovakia, Lithuania, Czech Republic, Luxembourg.

Those countries present some common characteristics that explain the status quo in the national implementation of the European open access policy. First, there are all (except from Estonia, Luxembourg and Czech Republic) countries that have gross domestic expenditures on research and development as a percentage of gross domestic product less than 1 [14] while the lower percentage is 0 and the higher is 3.5. Second, these countries are below average concerning the number of researchers (3127 researchers per million inhabitants). Third, they are countries that publish less than 1000 scientific articles per year except from Greece and Czech Republic. In short, there are quite small stakeholders on the European research scene.

We can easily deduce that in spite of the later realizable budget savings thanks to an open access to scientific publications [10], those countries cannot afford to set up infrastructures and open access funds. In some cases, the needed infrastructures exist but the will to implement an open access policy comes up against the lack of researchers awareness or an insufficient demand caused by the number of published articles at national level.

\subsection{Consultation in progress in order to implement a national policy}

Four European countries have not implemented a coordinated national policy yet but are on the right track. Indeed they launched a national consultation with all the stakeholders that should lead to the proposition of a bill. 
In Poland, a national consultation about open access to public resources was set off by Minister of Administration and Digitalization in 2012 [18]. Its aim was to define open access policy guidelines that will be integrated in a bill including open access to educative, cultural and scientific resources which will be publicly funded: the "Act on Open Public Resources". The fear not to afford open access gold in the long term, despite a continuous increasing of gross domestic expenditures on research and development as a percentage of gross domestic product since Poland joined the EU in 2004 (0.56 in 2004 and 0.74 in 2010 i.e. an increasing of 0.18 ) leads to favour green open access. Moreover, the Horizon 2020 framework forces Poland to increase the gross domestic expenditures on research and development as a percentage of gross domestic product to 1.7. It leads one to suppose a stepping up green open access support and an overcautious support to gold open access.

In Slovenia, any funder or institution have not yet formalized its support to open access by a mandate or a policy even if e-infrastructures came into being. However, the Research and Development Act states that results from publicly funded research must be accessible. The aim of the first period from 2011 to 2014 of the Resolution on the National Research and Development Programme 2011-2020 [12] was to launch a large national consultation with every stakeholder in order to establish some guidelines to a future bill that would include data too. The Plan on the National Research and Development Programme 2011-2020 also mention the connexion of all national repositories in CRIS (SICRIS [17]).

In the Netherlands, since 2009, Universities Rectors clearly indicated their commitment in favour of open access by conversing about the means to encourage the open access implementation. The VSNU (Vereniging Van Universiteiten) made an agreement with Springer in order that all the published articles written by dutch researchers and published by Springer's journals are in open access subject to author's permission. The NWO (Nederlandse Organisatie voor Wetenschappelijk Onderzoek), an independent research body which funds research and one of the biggest dutch funders, leads a strong policy in favour of open access notably the gold road by funding subsidies granting programmes to pay the author fees. For the time being there is no project of open access implementation policy.

In France, even if the Geneviève Fioraso's speech, Minister of Higher Education and Research, delivered on the 24th January 2013, indicated that "the French government reaffirm[ed] its support to open access to scientific information principle", the implementation of a mandatory open access policy is not approved unanimously notably among publishers in SHS. On one hand, there are the signatories of the 11th February 2013 "Open Access: le travail scientifique en SHS et le débat public fragilisés par les mesures préconisées par la Commission Européenne" that asks for "a real consultation on these issues with the public stakeholders, learned society, persons in charge of HHS journals and publishers" on the other hand the signatories of the opinion column "Qui a peur de l'Open Access?" in Le Monde dated the 15th March 2013 who do not consider open access as a threat for an economic model but as an opportunity for bibliodiversity and democratization of the access to research results. A national consultation was launched recently by the ministry of Higher Education and Research in order to establish what is the optimal embargo period for HHS journals. In April 2013, 26 research institutions signed a partnership agreement in order to encourage researchers to deposit their publications in HAL (ANR, INSERM, CNRS, etc.). Two national institutions have a mandatory deposit: IFREMER and INRIA.

\subsection{Funders mandates and policy}

Currently, in the UK, the gold road is more plebiscited than the green one even if the latter is not deserted. The Research Council UK (RCUK), a consortium of seven independent research councils, set up a gold open access policy. This policy was examined and an intermediate report [19] and is going to 
be reconsidered in the autumn 2014. Sixteen others funders also have their own open access policy, the list is available on SHERPA/RoMEO [16].

In Denmark, on the 22nd June 2012, the five principal national funders (Danish Council for Independent Research (DFF), the Danish Council for Strategic Research, the Danish National Research Foundations, the Danish Advanced Technology Foundation, and the Danish Council for technology and innovation) decided a common open access policy. This policy requires the deposit of a digital version of research articles in open archives within the six or twelve months after the article acceptance. Seven universities out of eight have an open access policy. However, it is often more a declaration of intent than a real mandate.

In Finland, even if the open access principle has been encouraged for a long time, concrete actions came into being just recently. The Science Academy that is the main funder recommands to researchers to publish in open access journals as often as possible. In 2011, the governmental programme promised to make accessible the digital resources managed by the public sector towards research and education and this in an interoperable format. In order to implement this programme, Minister of Education and Culture launched a project named TTA with the aim to create an open access national scientific policy and to build the necessary infrastructure. In 2013, a national bill circulated among the different stakeholders so they could make comments on it. This bill recommended either gold road or green road but set aside hybrid publications. An open access funding was set off. However, by the end of 2013, the TTA project was abandoned and a new proposal for the national open access policy was made by the Council for Finnish University Libraries for the Ministry of Education and Culture. This proposal uses the experiences from the mandates in Helsinki, Jyväskylä and Tampere universities.

In Sweden, two major funders, the Swedish Research Council and the Swedish Research Council for Environment, Agricultural Sciences and Spatial Planning (FORMAS), instituted open access mandate (green open access mandate concerning peer-reviewed articles to deposit in open archives within six months after publication) and the Association of Swedish Higher Education (SUHF) which recommends open access to its 41 institutions members and encourages these to institute their own open access policy. Recently, the Swedish Research Council (SRC) has been appointed by ministry in order to establish the guidelines of a national policy in favour of open access. The first version of this report should be published by the end of 2014.

In Austria, the open access movement is quite recent. Effectively, the first initiatives (notably this of University Rectors who advocated the implementation of a national open access policy) began in 2009. For two years, the rate has speeded up with the creation of some funders mandates notably the one of the Austrian Science Fund (FWF) that recommends to researchers to publish in open access journals, the fees being paid back by the dedicated fund and to deposit an electronic version in open archives within twelve months after publication. The Austrian Academy of Sciences (OAW) has a green open access policy but also has a publishing house that publishes gold open access journals and books. The University of Graz (KFU) is the first to make no secret about its open access policy by recommending strongly the green and gold roads. Others policies/institutional mandates should be set up soon but there is currently no expression of a need concerning the implementation of a national open access policy [1].

Hungary has a national research environment particularly active, fostered by the government and the Scientific Hungarian Research Funding (OKTA) which is the major funder. The OKTA policy encourages open access by requiring that the funded researchers publish in open access journals and deposit an electronic version into open archives. The only current open access government decree is about doctoral thesis ( ${ }^{\circ} 33$, 7th March 2007). 


\subsection{National policy coordinated by a recommendation}

In Belgium, exists a particularly active and innovative open access movement. However, it is really difficult to set up an open access national policy owing to the federalism that clearly complicates the coordination between different regional research environments, publishing stakeholders and linguistic issues. Nevertheless, the two major research funders FWO (Fonds Wetenschappelijk Onderzoek) in the Flemish Community and FNRS [8] (Fonds de la Recherche Scientifique) in the French Community both have a green open access mandate adopted in 2013 that needs a deposit of researchers' publications in open archives. A first step towards was the implementation of a national open access policy with the Brussels Declaration [3] on the 22nd October 2012 the signatories were the official ministers representatives of Paul Magnette (Walloon Region), Jean-Marc Nollet (Brussels Region) and Ingrid Lieten (Flemish Region). This Declaration defines a Belgian open access policy. The signatories committed themselves to encourage open access to the publicly funded research results by informing the researchers, by recommending them to make their publications available at the latest six months (STM) and twelve months (HHS) after publication, by examining the possibilities for the public funds to pay the open access publication fees, by encouraging the creation and preservation of deposit infrastructures, by thinking about the risks and opportunities of each open access road with the stakeholders. In the French Community, the dialogue between the actors (publishers and universities) of the French has turned into a consultation that could lead to embargo periods from six to twenty four months and even more for the publication in HSS. In the Flemish Community, EWI (departement Economie, Wetenschap en Innovatie) focus on open access on the 14th October 2013, one year after the Brussels Declaration, a day of debate between the different actors in order to think about the way to implement it at community level. However, up to now, there is no community policy.

In Ireland, there are four national open access funders mandates (Higher Education Authority (HEA), Health Research Board (HRB), Irish Research Council for Science, Engineering and Technology (IRCSET)) out of the seven national funders. The government announced on the 23rd October 2012 what were the open access national principles in National Principles for Open Access Policy Statement [13]. Among the major principles, we found a deposit obligation for scientific research publicly funded publications and an incentive to publish in open access journals. This recommendation favors the green road but does not definitely set aside the gold one. That fits with the creation of a dedicated fund in order to set up institutional deposits and a national portal whereas no specific fund has been launched to finance the gold road.

In Portugal, some open access initiatives have been set up since 2004 with notably the University of Minho's institutional repository. Although the Portuguese government, the public and private funders have officially not announced open access policies or mandates yet, the Conference of Portuguese University rectors (CRUP) recommends to the research bodies to implement a mandated repository policy for research publications and data. The CRUP trusts to the generalization of an only open access European mandate that could lead to a lack of a national mandate implementation. On 5th May 2014, the Fundação para a Ciência e a Tecnologia which is the central Portuguese governmental institution responsible for financing and evaluating the scientific and technological research adopted a national mandate. This requires that researchers final version publications funded totally or partially but the FCT are deposited in a repository which belongs to RCAAP network not later than the publication. The embargo periods are twelve months for HSS and six months for STM. Monographs and books chapters are also concerned by this mandate. 
In Croatia, there is a scientific open access community, particularly active through four institutional repositories and one national portal that makes accessible more than 250 scientific Croatian journals (HRCAK). Currently, there is no Croatian open access funder mandate. The document Science and technology policy of the Republic of Croatia 2007-2010 issued by the ministry of Science, Education and Sports mentions that the publicly funded research results have to be accessible to the general public thanks to open access publications or databases. On the 24th October 2012, a national declaration was publicized [4].

\subsection{National policy coordinated by a law}

In Latvia, the national research funders have no open access define policy but with the aim of increasing visibility and impact of national research, several institutions and researchers publish in open access journals and deposit their work into institutional repositories. The adoption of the national reform programme for the implementation of European strategy "Horizon 2020" by the Latvian Cabinet have not led to the adoption of open access policies or mandates by the funders or the government in the long term. However, this programme mentions an obligation to deposit publicly funded research publications into repositories (embargo period up to six months in STM and twelve in SHS) and the creation of subsidies for gold open access journals.

Spain was the first state to legislate on open access, from 2011, with the "Ley de la Ciencia, la Tecnología y la Innovación" [11]. The implementation of this law is not very much prejudicial to publishers insofar it maintains the editorial embargo as it is mentioned in article 37 paragraph 3.

In Germany, the law dated July 2013 about orphan and unavailable works includes a clause about open access. This clause gives to the authors a right of secondary publication. This allows to take similar but non-profit publication by the author twelve months after the article acceptance in STM and SHS. This right is applied if the research work is publicly funded and if the article is accepted in a journal that is published at least twice a year. This settlement affirmed its superiority on the contract because it is mentioned that "every agreement that goes in the opposite direction to the detriment of the author would be considered as ineffective".

In Italy, in March 2013, the major research bodies Presidents, associated with the Conference of Italian University rectors signed a declaration in favour of open access. In October 2013, the legislator intervened on open access regarding a decree-law about preservation and restoration of cultural goods. It establishes the guidelines for the funding bodies in order to promote open access and it mentions embargo periods and contents which are concerned. However, whereas the initial bill planned an open access to the articles six months after publication, the bill which was adopted on the 8th October 2013 requires embargo periods of 18 months in STM and 24 months in SHS and books are not concerned. This modification of the first version of the bill is the consequence of an important work of lobbying that was done by private Italian publishers who considers that a six months embargo period is insufficient to assure the economic viability of publications.

\section{Conclusion}

As a warning, it is important to be aware of the fact that this research is a snapshot of a situation at a given time. Indeed, the data evolve with time and need to be reactualized permanently. 
As a conclusion, there some obstacles to harmonization and to simplify the publishing process for researchers that are emerging because of these various levels of implementation of the EC recommendation and intrinsic differences between the national policies. Here are some examples in order to support this point:

First, gold funds are not available in each country so if a researcher belongs to a country that made the choice to support open access gold and wants to publish in a country without gold open access journals because of it supports green open access, couldn't it be detrimental in the evaluation process of this researcher? In the same way, if the researcher belongs to a country which have no gold open access funds and wants to publish in a gold open access journal who is going to pay the bill?

Second, there are political constraints on open access at a national level that could be considered to conflict with other national political constraints at an European level. How to find an agreement in order not to prejudice international collaborations and mobility?

Third, legislative framework around the independence of the researchers are not the same in each country. Some are really attached to the fact that the researcher must be free to publish where he wants to publish. This philosophy translated into law could create lack of understanding and inequalities between the researchers at an European level.

We notice that there is a birth of asymmetries or a more complex publishing process for researchers because of all these national policies which are quite aligned on the EC recommendation but not to the same extent. This goes against the globalization of research and the need for European research to overcoming the barriers in order to strengthen is worldwide position in research. Moreover, imbalances have emerged for the publishers since the beginning of the EC recommendation implementation. That brings us to the question of who exactly is really benefiting from Open access, the researchers of countries that lead the world in scientific output or these that run behind? In order to answer to this question, two specificities need to be considered: the specific language of papers production and the scientific discipline anchorage either in human sciences or in hard sciences. As a consequence, this issue will be the subject for further research on the future of non-English-speaking national publishing in the context of the EU recommendation.

\section{References}

[1] Australian Government, The Austrian Research and Technology Report 2013, 2013, Chapter on "Open Access", available at: http://www.bmvit.gv.at/en/service/publications/downloads/downloads_ftb/ftb_2013_en.pdf.

[2] BASE - Bielfield academic search engine, available at: http://www.base-search.net/about/en/.

[3] Brussels Declaration on Open Access, available at: http://openaccessbelgium.files.wordpress.com/2012/10/brusselsdeclaration-on-open-access.pdf.

[4] Croatian Open Access Declaration, available at: http://www.fer.unizg.hr/oa2012/declaration.

[5] ERA progress report 2013, available at: http://ec.europa.eu/research/era/pdf/era_progress_report2013/era_progress_ report2013.pdf.

[6] European Commission communication towards better access to scientific information, available at: http://ec.europa.eu/ research/science-society/document_library/pdf_06/era-communication-towards-better-access-to-scientific-information_ fr.pdf.

[7] European Commission recommendation on access and preservation scientific information, available at: http://ec.europa. eu/research/science-society/document_library/pdf_06/recommendation-access-and-preservation-scientific-information_ en.pdf.

[8] FRS-FNRS Reglement on Open Access, available at: http://www.frs-fnrs.be/uploaddocs/docs/SOUTENIR/FRS-FNRS_ Reglement_OPEN_ACCESS.pdf.

[9] Global Open Access Portal, available at: http://www.unesco.org/new/en/communication-and-information/portals-andplatforms/goap/access-by-region/. 
[10] J. Houghton, Open Access - What are the economic benefits? A comparison of the United Kingdom, Netherlands and Denmark, Knowledge Exchange, 2009, available at: http://www.knowledge-exchange.info/default.aspx?id=316.

[11] Ley 14/2011, de 1 de junio, de la Ciencia, la Tecnología y la Innovación, available at: https://www.boe.es/boe/dias/ 2011/06/02/pdfs/BOE-A-2011-9617.pdf.

[12] Nacionalni Program Visokega Šolstva 2011-2020, available at: http://www.arhiv.mvzt.gov.si/fileadmin/mvzt.gov.si/ pageuploads/pdf/znanost/RISS/NRRI.pdf.

[13] National Principles for Open Access Policy Statement, available at: http://www.tcd.ie/Library/assets/pdf/National\%20 Principles\%20on\%20Open\%20Access\%20Policy\%20Statement\%20(FINAL\%2023\%20Oct\%202012\%20v1\%203).pdf.

[14] OCDE, Gross domestic expenditure on R\&D, Science and Technology: Key Tables from OECD, No. 1, 2013, doi:10.1787/rdxp-table-2013-1-en.

[15] OpenAIRE - Open Access Infrastructure Research for Europe, available at: http://www.openaire.eu/fr.

[16] SHERPA-RoMEO, available at: http://www.sherpa.ac.uk/juliet/index.php.

[17] Slovenian Current Research Information System, available at: http://www.sicris.si/default.aspx?lang=eng.

[18] SPARC Europe news, available at: http://sparceurope.org/polish-ministry-of-administration-digitization-great-debate-onopen-public-resources/.

[19] The implementation of open access Report, House of lords, 3rd Report of Session 2012-13, available at: http://www. publications.parliament.uk/pa/ld201213/ldselect/ldsctech/122/122.pdf. 